\title{
Acute Respiratory Disease in US Army Trainees 3 Years after Reintroduction of Adenovirus Vaccine ${ }^{1}$
}

\section{Nakia S. Clemmons, ${ }^{2}$ Zachary D. McCormic, Joel C. Gaydos, Anthony W. Hawksworth, Nikki N. Jordan}

The 1999 cessation of vaccination against adenovirus types 4 and 7 among US Army trainees resulted in reemergence of acute respiratory disease (ARD) outbreaks. The $2011 \mathrm{im}$ plementation of a replacement vaccine led to dramatic and sustained decreases in ARD cases, supporting continuation of vaccination in this population at high risk for ARD.

$\mathrm{I}^{\mathrm{n}}$ $n$ the past, febrile acute respiratory disease (ARD) was a major cause of illness among military members, especially those in initial entry training (IET [basic training]), a physically and mentally demanding 6 - to 12 -week program (1-5). Most cases were caused by infection with adenovirus types 4 and $7 ; 80 \%$ of trainees became infected and $20 \%$ were hospitalized (5).

Routine use of oral adenovirus type 4 and 7 (AdV4 and -7) vaccine began in 1971 and eventually included year-round vaccination, resulting in plummeting ARD rates (1). In 1994, the sole vaccine manufacturer stopped production. The last doses were shipped in 1996 and administered only during winter until stocks were depleted in 1999; ARD rates subsequently increased at IET sites $(3,4)$.

When the stock of AdV-4 and -7 vaccine was depleted, the Army's Acute Respiratory Disease Surveillance Program (ARD-SP), partnering with the Naval Health Research Center (San Diego, CA, USA) Febrile Respiratory Illness (NHRC FRI) Surveillance Program, demonstrated substantial increases in ARD cases, specifically adenovirus-associated ARD. These cases cost $\approx \$ 10-\$ 26$ million each year in medical care and lost recruit time (5). In addition, a threat existed for the emergence of other adenovirus types that could cause severe and fatal disease (5). In March 2011, a new, 2-tablet, live, enteric-coated oral AdV-4 and -7 vaccine was licensed by the US Food and Drug Administration for use in US military members. Administration of the vaccine to trainees early in their IET

Author affiliations: US Army Public Health Center, Aberdeen

Proving Ground, Maryland, USA (N.S. Clemmons, Z.D. McCormic,

J.C. Gaydos, N.N. Jordan); US Naval Health Research Center,

San Diego, California, USA (A.W. Hawksworth)

DOI: http://dx.doi.org/10.3201/eid2301.161297 program began in November 2011 and reached full coverage of all trainees by year's end. In 2014, NHRC reported that, after 2 years of AdV-4 and -7 vaccine use, a dramatic decline was seen in febrile ARD cases in training centers across the military services, and no indication was seen of a serious, sustained emergence of a new adenovirus threat (5). We report the ARD-SP and NHRC FRI data for the US Army IET population during the first 3 years after reintroduction of AdV-4 and -7 vaccine, looking at variations in ARD rates at 4 Army IET sites and at adenovirus types identified in trainees with ARD.

\section{The Study}

In 1966, the ARD-SP, then called the Adenovirus Surveillance Program, was implemented to monitor ARD and evaluate the new AdV-4 and -7 vaccine at IET sites (2). In 1996, partly in response to increasing ARD cases, the NHRC initiated the FRI Surveillance Program to assess febrile respiratory illness rates, etiologies, and trends across military training installations (5). ARD-SP captured all ARD cases, and NHRC FRI collected respiratory specimens from a convenience sample of the ARD-SP cohort. This subset was tested for respiratory pathogens, including adenoviruses. Together, the ARD-SP, operated by the Army Public Health Center (Aberdeen Proving Ground, MD), and the NHRC FRI program have provided coordinated surveillance of respiratory pathogens for Army IET populations.

We studied aggregate data from 2010-2014 from the ARD-SP and NHRC FRI programs. The Army Public Health Center collected weekly ARD-SP data from the Army's 4 IET sites (Fort Benning, GA; Fort Jackson, SC; Fort Leonard Wood, MO; and Fort Sill, OK). ARD case criteria were oral temperature $\geq 100.5^{\circ} \mathrm{F}$, recent sign or symptom of acute respiratory tract inflammation, and having a limitation in training or removal from duty. We determined ARD rates for each IET installation and for the total Army IET population using the equation (ARD cases/all trainees) $\times$ 100 trainee weeks, and used SPSS version 21 (SPSS, Inc., Chicago, IL, USA) for analyses.

${ }^{1}$ Preliminary results from this study were presented at the IDWeek 2014 meeting, October 8-12, 2014; Philadelphia, Pennsylvania, USA.

${ }^{2}$ Current affiliation: Centers for Disease Control and Prevention, Atlanta, Georgia, USA. 
Table. Rate of ARD cases and percent change by year at 4 US Army initial entry training sites, 2010-2014*

\begin{tabular}{lccccc}
\hline & \multicolumn{4}{c}{ Average ARD rate $(\%$ change), by training site $\dagger$} \\
\cline { 2 - 5 } Year & Fort Benning & Fort Jackson & Fort Sill & Fort Leonard Wood & Overall $\dagger$ \\
\hline 2010 & 0.29 & 0.67 & 0.20 & 0.43 & 0.43 \\
2011 & $0.18(-38)$ & $0.44(-34)$ & $0.75(+275)$ & $0.35(-19)$ & $0.39(-9)$ \\
2012 & $0.06(-79)$ & $0.08(-88)$ & $0.19(-5)$ & $0.08(-81)$ & $0.09(-79)$ \\
2013 & $0.06(-79)$ & $0.09(-87)$ & $0.13(-35)$ & $0.08(-81)$ & $0.08(-81)$ \\
2014 & $0.04(-86)$ & $0.07(-90)$ & $0.08(-60)$ & $0.05(-88)$ & $0.06(-86)$ \\
\hline
\end{tabular}

${ }^{*}$ The adenovirus vaccine program was reintroduced in November 2011 and rate changes were studied through 2014. ARD, acute respiratory disease. tARD rate $=(A R D$ cases/all trainees $) \times 100$ trainee weeks. $\%$ change calculated from last full year before vaccination (i.e., 2010).

An ongoing program of year-round administration of AdV-4 and -7 vaccine at Army IET sites began in November 2011. Overall, ARD rates decreased in November 2011 (9\% from 2010 rates) and each subsequent year through 2014 (Table). However, in 2011, Fort Sill experienced an increase over 2010 ARD rates before rates dropped substantially in 2012 ( 0.75 cases/100 trainee weeks in 2011 vs. 0.19 cases/100 trainee weeks in 2012) and remained low through 2014 (Figure 1; Table). All 4 sites experienced similar declines from 2010 to 2014, ranging from $60 \%$ to $90 \%$ (Table). The combined mean ARD rate for 2010 was 7 times higher than that for 2014 ( 0.43 cases/100 trainee weeks vs. 0.06 cases/100 trainee weeks, respectively).

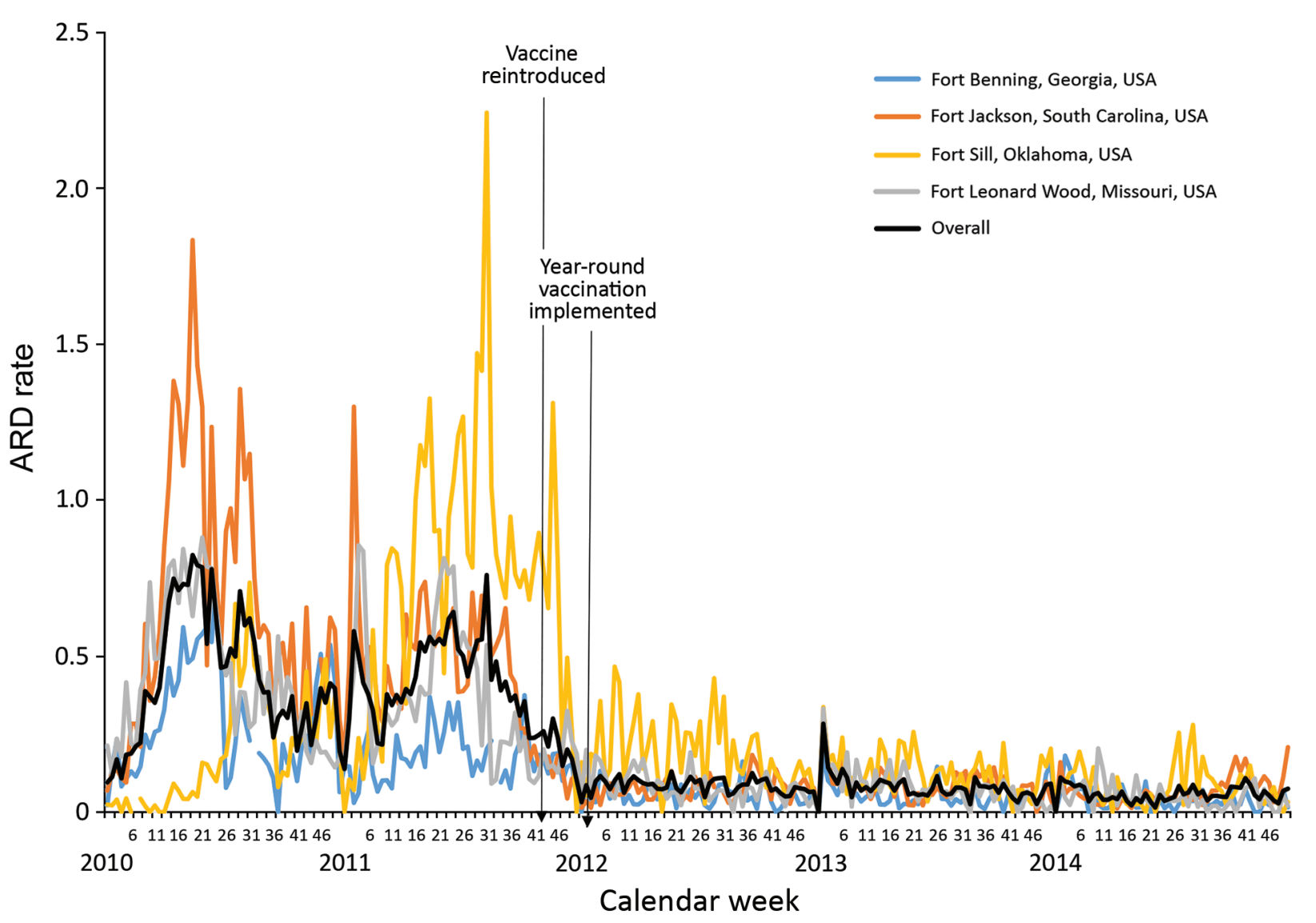

Figure 1. Weekly acute respiratory disease (ARD) rates by US Army initial entry training site, 2010-2014. ARD rate $=($ ARD cases/all trainees) $\times 100$ trainee weeks.
Prior to implementation of the new vaccine in 2011, adenovirus type 4 was the predominant type at all training sites $(86 \%)$, followed by types $3(7 \%)$ and $7(5 \%)$. After the reintroduction of adenovirus vaccine, most (71\%) adenovirus-positive specimens from 2012-2014 were positive for adenovirus types 1 and 2 (Figure 2). However, appearances of adenovirus types 1 and 2 were small in scale and scattered over place and time.

\section{Conclusions}

Reintroduction of AdV-4 and -7 vaccine had a profound effect at all Army IET sites; the combined ARD rate decreased from 0.43 cases $/ 100$ trainee weeks in 2010 to 0.06 cases $/ 100$ trainee weeks in $2014(\mathrm{p}<0.001)$, and adenovirus 


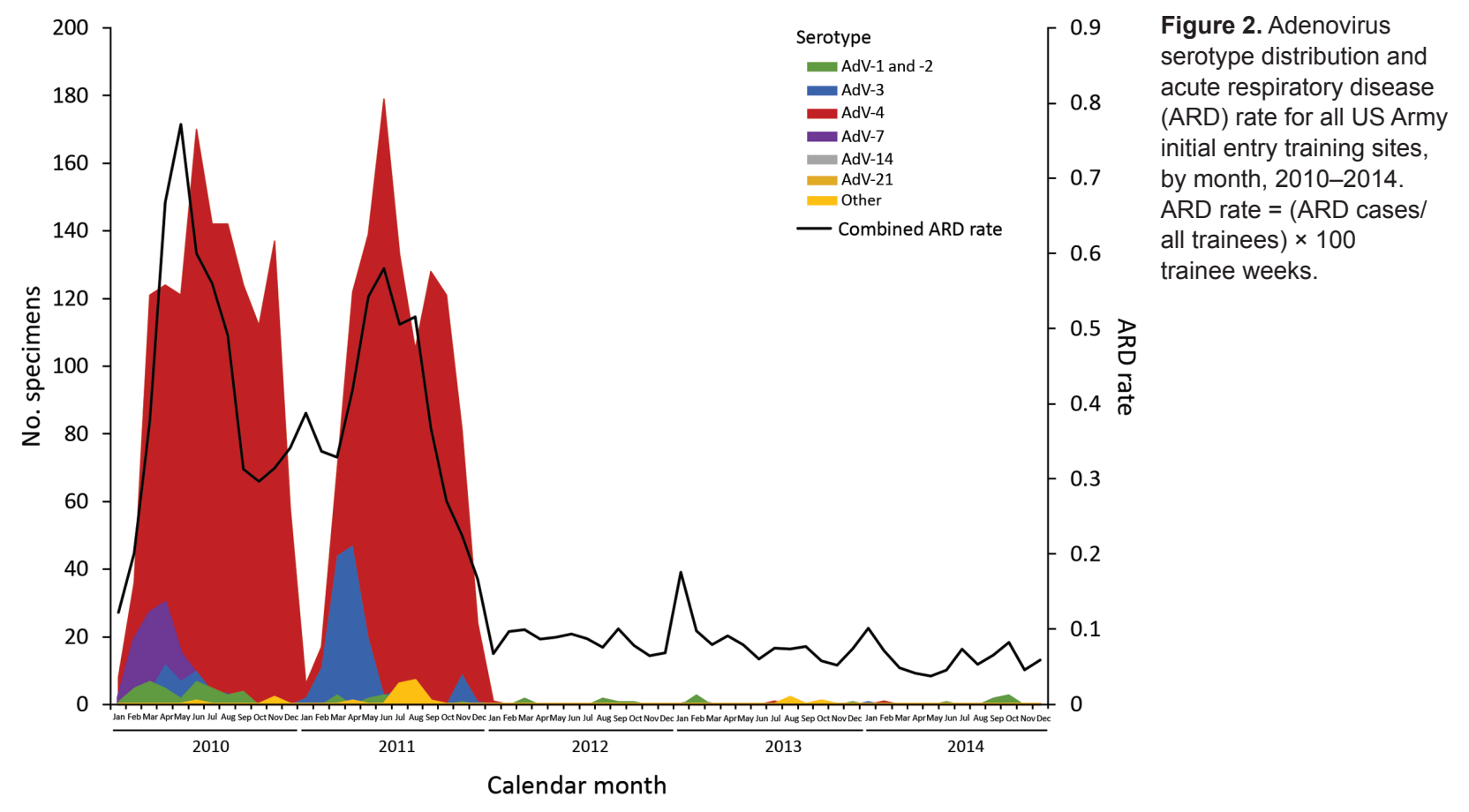

was identified only sporadically in ill trainees. Although a low level of ARD activity, caused by many different agents, has persisted since reestablishment of the vaccine program, the vaccine has effectively controlled the major cause of ARD at IET sites at the low cost of $\$ 150 /$ trainee (5).

The increased average ARD rate for Fort Sill during 2011 was likely an anomaly associated with a lapse in the military's long-standing routine use of benzathine penicillin $\mathrm{G}$ prophylaxis for group A $\beta$-hemolytic streptococcus infections coupled with a surveillance artifact introduced when Fort Sill made enhancements to their ARD surveillance program (2,0). After benzathine penicillin G prophylaxis was reintroduced, ARD rates substantially decreased in 2012, mirroring reductions observed at other IET sites after adenovirus vaccine administration.

Vaccination administration has multiple benefits. A study of US Air Force trainees with acute respiratory illness found decreased severity of systemic symptoms and reduced fever and heart rate in those who became ill after the vaccine was reintroduced (7). In addition, we observed an overall decrease in ARD rates and suppression of nearly all adenovirus types. Since introduction of the vaccine in 1971, many have suggested that this vaccine may have an effect on reducing ARD caused by agents other than adenovirus types 4 and 7 . Recent studies have shown the AdV-4 and -7 vaccine to have a potentially broader effect, as demonstrated by decreased rates of overall febrile illness among trainees and other service members $(8-10)$. This effect could be due to activation of innate immunity and heterotypic antibody response $(11,12)$.

The overall observed reduction in ARD among Army IET trainees translates to substantial cost savings by reducing the probability of severe illness or death and lost training time. During the 1999-2010 lapse in adenovirus vaccine coverage, 8 adenovirus-infected service members died (13). Estimates showed each infection costs $\approx \$ 3,838$, and each year the vaccine prevents 1 death, $1,100-2,700$ hospitalizations, and 13,000 febrile infections among military recruits. Vaccination costs $\$ 150$ per person, providing a net savings of $\approx \$ 20$ million (5). Phase 3 safety studies of the vaccine established an excellent safety profile (14). Surveillance safety data since 2011 should be released soon and are expected to be consistent with the Phase 3 data.

The AdV-4 and -7 vaccine may have applications beyond the US military. Adenovirus outbreaks have occurred in non-US military populations and facilities where close contact and suboptimal hygiene may be present (e.g., militaries of other countries, dormitories, and healthcare facilities). In addition to the US military, populations in those and similar settings may benefit from AdV-4 and -7 vaccine (15).

\section{Acknowledgments}

We thank the ARD-SP and FRI program teams at Fort Benning, Fort Sill, Fort Jackson, and Fort Leonard Wood for their support and commitment to the programs and Philip K. Russell for his review of this work and his advice.

Ms. Clemmons is an epidemiologist in the National Center for Immunization and Respiratory Diseases at the Centers for Disease Control and Prevention. Her research interests are infectious and environmental diseases. 


\section{References}

1. Gray GC, Callahan JD, Hawksworth AW, Fisher CA, Gaydos JC. Respiratory diseases among U.S. military personnel: countering emerging threats. Emerg Infect Dis. 1999;5:379-85. http://dx.doi.org/10.3201/eid0503.990308

2. Lee SE, Eick A, Ciminera P. Respiratory disease in army recruits: surveillance program overview, 1995-2006. Am J Prev Med. 2008:34:389-95. http://dx.doi.org/10.1016/j.amepre.2007.12.027

3. Gray GC, Goswami PR, Malasig MD, Hawksworth AW, Trump DH, Ryan MA, et al.; Adenovirus Surveillance Group. Adult adenovirus infections: loss of orphaned vaccines precipitates military respiratory disease epidemics. Clin Infect Dis. 2000;31:663-70. http://dx.doi.org/10.1086/313999

4. Kolavic-Gray SA, Binn LN, Sanchez JL, Cersovsky SB, Polyak CS, Mitchell-Raymundo F, et al. Large epidemic of adenovirus type 4 infection among military trainees: epidemiological, clinical, and laboratory studies. Clin Infect Dis. 2002;35:808-18. http://dx.doi.org/10.1086/342573

5. Radin JM, Hawksworth AW, Blair PJ, Faix DJ, Raman R, Russell KL, et al. Dramatic decline of respiratory illness among US military recruits after the renewed use of adenovirus vaccines. Clin Infect Dis. 2014;59:962-8. http://dx.doi.org/10.1093/cid/ ciu507

6. Broderick MP, Hansen CJ, Russell KL, Kaplan EL, Blumer JL, Faix DJ. Serum penicillin G levels are lower than expected in adults within two weeks of administration of 1.2 million units. PLoS One. 2011;6:e25308. http://dx.doi.org/10.1371/journal. pone. 0025308

7. Yun HC, Young AN, Caballero MY, Lott L, Cropper TL, Murray CK. Changes in clinical presentation and epidemiology of respiratory pathogens associated with acute respiratory illness in military trainees after reintroduction of adenovirus vaccine. Open Forum Infect Dis. 2015;2:ofv120. http://dx.doi.org/10.1093/ofid/ofv120

8. O'Donnell FL, Taubman SB. Follow-up analysis of the incidence of acute respiratory infections among enlisted service members during their first year of military service before and after the 2011 resumption of adenovirus vaccination of basic trainees. MSMR. 2015;22:2-7.

9. Hoke CH Jr, Hawksworth A, Snyder CE Jr. Initial assessment of impact of adenovirus type 4 and type 7 vaccine on febrile respiratory illness and virus transmission in military basic trainees, March 2012. MSMR. 2012;19:2-4.

10. Hawksworth A. Surveillance snapshot: adenovirus among US military recruit trainees. MSMR. 2012;19:5.

11. Thaci B, Ulasov IV, Wainwright DA, Lesniak MS. The challenge for gene therapy: innate immune response to adenoviruses. Oncotarget. 2011;2:113-21. http://dx.doi.org/10.18632/oncotarget.231

12. Grayston JT, Johnston PB, Loosli CG, Smith ME, Woolridge RL. Neutralizing and complement fixing antibody response to adenovirus infection. J Infect Dis. 1956;99:199-206. http://dx.doi.org/10.1093/infdis/99.2.199

13. Potter RN, Cantrell JA, Mallak CT, Gaydos JC. Adenovirusassociated deaths in US military during postvaccination period, 1999-2010. Emerg Infect Dis. 2012;18:507-9. http://dx.doi.org/10.3201/eid1803.111238

14. Kuschner RA, Russell KL, Abuja M, Bauer KM, Faix DJ, Hait H, et al.; Adenovirus Vaccine Efficacy Trial Consortium. A phase 3, randomized, double-blind, placebo-controlled study of the safety and efficacy of the live, oral adenovirus type 4 and type 7 vaccine, in US military recruits. Vaccine. 2013;31:2963-71. http://dx.doi.org/10.1016/j.vaccine.2013.04.035

15. Sivan AV, Lee T, Binn LN, Gaydos JC. Adenovirus-associated acute respiratory disease in healthy adolescents and adults: a literature review. Mil Med. 2007;172:1198-203. http://dx.doi.org/10.7205/MILMED.172.11.1198

Address for correspondence: Nakia S. Clemmons, Centers for Disease Control and Prevention, 1600 Clifton Rd, Mailstop A34, Atlanta, GA 30329-4027, USA; email: nclemmons@cdc.gov

\section{Get the content you want delivered to your inbox.}

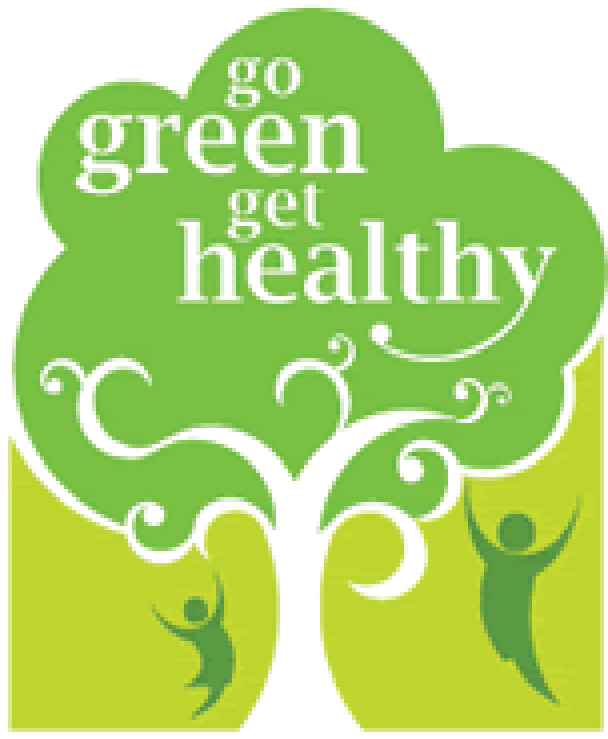

- Table of Contents

- Podcasts

- Ahead of Print articles

- CME

- Specialized Content

\section{Online subscription: wwwnc.cdc.gov/eid/subscribe/htm}

